\title{
Da ambiguidade discursiva às possibilidades de ação no campo da Educação Inclusiva em Portugal
}

From the discursive ambiguity to the possibilities of action in the area of Inclusive Education in Portugal

La ambigüedad discursiva a las posibilidades de acción en el campo de la Educación Inclusiva en Portugal

\author{
* Robson Celestino Prychodco \\ Doutorando pela Universidade do Porto (Portugal) e Universidade Estadual de Campinas, \\ Campinas, São Paulo, Brasil. \\ robsilcel@gmail.com

\section{${ }^{* *}$ Preciosa Fernandes} \\ Professora Doutora da Universidade do Porto, Porto, Portugal. \\ preciosa@fpce.up.pt
}

\section{*** Zélia Lourenço de Camargo Bittencourt \\ Doutora pela Universidade Estadual de Campinas, Campinas, São Paulo, Brasil. zeliaz@fcm.unicamp.br}

Recebido em 27 de março de 2019

Aprovado em 14 de abril de 2019

Publicado em 12 de setembro de 2019

\section{RESUMO}

Historicamente, o atendimento de alunos com deficiências e/ou com Necessidades Educativas Especiais (NEE) esteve remetido às respostas amparadas em visões segregacionistas e excludentes (FREITAS, 2008). Contudo, uma nova compreensão, alicerçada no reconhecimento e no respeito à diversidade, pôs no centro do debate político e acadêmico propósitos de uma Educação Inclusiva (AINSCOW, 2009) requerendo às escolas e professores respostas educativas diferenciadas. Para compreender esta mudança paradigmática recorre-se a uma leitura que relaciona os Modelos Biomédico, Social e Biopsicossocial (MARCO, 2006) com os paradigmas educativos da Exclusão (ou Segregação), Integração e Inclusão (SASSAKI, 2006). Tendo este enquadramento por base, o artigo apresenta um estudo realizado com 12 professoras que trabalham no campo da Educação Inclusiva na região do Grande Porto-Portugal. Trata-se de pesquisa qualitativa que teve como objetivos: identificar as concepções de Educação Inclusiva das professoras e compreender, numa relação com os Modelos Biomédico, Social e Biopsicossocial, quais as possibilidades para concretização dessa filosofia educativa no cotidiano escolar. Após a coleta dos dados, que se deu por meio de entrevistas semiestruturadas, os discursos foram 
transcritos e analisados com suporte do Software Nvivo. Os resultados apontaram para uma ambiguidade discursiva que se reflete não apenas nas concepções das professoras relativamente à educação inclusiva, como também se relaciona às práticas no campo da intervenção na escola.

Palavras-chave: Escola Inclusiva; Exclusão, Integração e Inclusão; Modelos Biomédico, Social e Biopsicossocial.

\section{ABSTRACT}

Historically, attendance of students with disabilities and / or Special Educational Needs has been remitted to answers based on segregationist and exclusionary views (FREITAS, 2008). However, a new understanding, grounded in the recognition and respect for diversity, placed at the center of the political and academic debate the principles of an Inclusive Education (AINSCOW, 2009) requiring differentiated educational responses from schools and teachers. In order to understand this paradigm change, a reading that links the Biomedical, Social and Biopsychosocial Models (MARCO, 2006) with the educational paradigms of Exclusion (or Segregation), Integration and Inclusion (SASSAKI, 2006) was used. Based on this framework, the article presents a study using 12 teachers working in the field of Inclusive Education in Greater Porto-Portugal. It is a qualitative research that had as objectives: to identify the conceptions of Inclusive Education of the teachers and to understand, in relation with the Biomedical, Social and Biopsychosocial Models, the possibilities for the concretization of this educational philosophy in school on a daily basis. After the data collection, which took the form of semi-structured interviews, the speeches were transcribed and analyzed with the support of Nvivo Software. The results pointed to a discursive ambiguity that is reflected not only in the teachers' conceptions regarding inclusive education, but also relates to practices in the intervention at school field.

Keywords: Inclusive School; Exclusion, integration and inclusion; Biomedical, Social and Biopsychosocial Models.

\section{RESUMEN}

Históricamente, la atención de alumnos con discapacidades y / o con Necesidades Educativas Especiales estuvo remitida a las respuestas amparadas en visiones segregacionistas y excluyentes (FREITAS, 2008). Sin embargo, una nueva comprensión, basada en el reconocimiento y el respeto de la diversidad, puso en el centro del debate político y académico los principios de una Educación Inclusiva (AINSCOW, 2009) requiriendo de las escuelas y profesores respuestas educativas diferenciadas. Para comprender este cambio paradigmático se recurre a una lectura que relaciona los modelos Biomédico, Social y Biopsicosocial (MARCO, 2006) con los paradigmas educativos de la Exclusión (o segregación), Integración e Inclusión (SASSAKI, 2006). Teniendo este marco de trabajo basado, el artículo presenta un estudio de 12 profesores que trabajan en el campo de la educación inclusiva en el Gran Porto-Portugal. Se trata de una investigación cualitativa que tuvo como objetivos: identificar las concepciones de Educación Inclusiva de 
las profesoras y comprender, en una relación con los Modelos Biomédico, Social y Biopsicosocial, cuáles las posibilidades para concreción de esa filosofía educativa en el cotidiano escolar Después de la recolección de los datos, que se dio por medio de entrevistas semiestructuradas, los discursos fueron transcritos y analizados con soporte del Software Nvivo. Los resultados apuntan a una ambigüedad discursiva que se refleja no sólo en las concepciones de las profesoras en cuanto a la educación inclusiva, sino que se relaciona con las prácticas en el campo de la intervención en la escuela.

Palabras clave: Escuela Inclusiva; Exclusión, Integración e Inclusión; Modelos Biomédicos, Social y Biopsicosocial.

\section{Introdução}

Um dos maiores desafios colocado à escola diz respeito a sua capacidade de incluir a todos. Segundo Booth e Ainscow (2002), a inclusão destina-se a todos os alunos, não se restringindo apenas àqueles que são identificados como sendo da "Educação Especial". Essa visão é corroborada por inúmeros documentos internacionais, desde logo pela Declaração de Salamanca (1994) pela Policy Guidelines on Inclusion in Education (2009), e, mais recentemente, pelo Guide for Ensuring Inclusion and Equity in Education (2013) e pela Declaração de Incheon (2015). Essa perspectiva está alicerçada na ideia de que, para ser considerada inclusiva, a escola precisa combater barreiras e/ou restrições existentes no campo da aprendizagem e da participação dos alunos que possam colocá-los em situações de vulnerabilidade e de exclusão, e/ou contribuir para perpetuar estigmas e preconceitos.

A diversidade de características e necessidades da população em idade escolar representa, ao mesmo tempo, uma grande riqueza para a escola, mas também um contínuo desafio, impelindo-a para uma busca permanente por respostas pedagogicamente diferenciadas. Todavia, para que a escola seja capaz de prover tais respostas, a inclusão deve ser compreendida como uma prática educativa destinada a todos os alunos, independentemente da sua situação de vulnerabilidade. Com efeito, estar numa situação de vulnerabilidade pode ser indicativo de um amplo leque de situações, desde desvantagens sociais, intelectuais, motoras, emocionais e sensoriais, pertença a minorias étnico-raciais e a meios socioeconômicos estigmatizados, nacionalidade, língua; orientação política sexual ou religiosa contra-hegemônica; problemas de ordem familiar, dificuldades acentuadas de aprendizagem, entre outros aspectos (ABRAMOVAY et al, 2002; SOUSA; FARIA, 2017; OVIEDO; CZERESNIA, 2015). 
Reconhecer que alguns desses fatores podem produzir segregação no interior da escola, e mesmo a exclusão dos alunos que as experimentam, exige da escola suprema atenção no sentido de eliminar as barreiras que afetam cada aluno e criar condições para a sua inclusão. Nessa perspectiva, o respeito às diferenças implica acolher e promover todas as acessibilidades necessárias para que a aprendizagem de cada aluno se faça de forma significativa (SASSAKI, 2003; 2009).

Ainda, de acordo com Sassaki (2009), existem 6 dimensões relacionadas com a acessibilidade, a saber: 1) arquitetônica, que diz respeitos às barreiras físicas de cada ambiente; 2) comunicacional, que trata das barreiras na comunicação entre as pessoas; 3 ) metodológica, relativa às barreiras nos métodos e técnicas utilizadas; 4) instrumental, relacionada com instrumentos, mobiliário, ferramentas, utensílios utilizados no cotidiano; 5) programática, associada às diretrizes de políticas públicas, legislações e documentos oficiais e a 6) atitudinal, referente a preconceitos, estereótipos, estigmas e discriminações enfrentadas por pessoas que não se encaixam nos padrões socialmente valorizados, especialmente as pessoas com Alterações nas Funções e Estruturas do Corpo (AFEC).

Nesta complexidade de situações, uma questão pode ser colocada: como enfrentar o desafio da Educação Inclusiva numa escola que, em termos de currículo, expectativas, estruturas físicas etc, foi pensada como se todos os alunos fossem iguais, aprendessem ao mesmo tempo e da mesma maneira (RODRIGUES, 2017). Enfim, o paradoxo reside na necessidade de incluir a todos, respeitando-se a diversidade que caracteriza os grupos humanos, num sistema que parece ter sido preparado para a homogeneidade.

No que respeita à realidade portuguesa, em termos de política educativa, é, sobretudo, a partir da Lei de Bases do Sistema Educativo (PORTUGAL, 1986) que o desafio da Inclusão é enunciado. Desde então, várias medidas educativas vêm sendo implementadas no sentido de atender à diversidade dos alunos, requerendo às escolas e aos professores novas propostas educativas. Nesse percurso das políticas públicas, um exemplo recente de transição conceitual pode ser percebido com a publicação do DecretoLei 54/2018, normativo que regulamenta a educação inclusiva atualmente. Percebe-se que a concepção de inclusão restrita, definida por critérios de ordem biomédica, como preconizado no Decreto-Lei 319/91 e, ainda que de forma não tão explícita, no Decreto-Lei 3/2008, foi substituída por uma concepção mais ampla, que subscreve uma visão de escola inclusiva como contexto "onde todos e cada um dos alunos, independentemente da sua 
situação pessoal e social, encontram respostas que lhes possibilitam a aquisição de um nível de educação e formação facilitadoras da sua plena inclusão social" (DIÁRIO DA REPÚBLICA, 2019, p.2918). Nessa referência à inclusão social, podemos vislumbrar orientações que se a aproximam das características do Modelo Social (DINIZ, 2003).

Nesta trajetória, o papel dos professores de Educação Especial também muda. Se antes, no quadro das orientações previstas no Decreto-Lei 319 /91, esse profissional representava um recurso do/para o aluno com deficiência e/ou NEE, em proximidade com a perspectiva do Modelo Biomédico, no contexto do Decreto-Lei 3/2008 e, de modo mais claro, na atualidade (Decreto-Lei 54/2018), o professor de Educação Especial é um recurso da escola, responsável pela interlocução com a família e demais intervenientes da Saúde, Assistência Social e comunidade, o que amplia seu leque de ações para além da atuação docente, tornando-o uma espécie de "articulador" de processos inclusivos. Essa nova acepção de "ser professor de Educação Especial" aproxima-se da perspectiva do Modelo Biopsicossocial. A inclusão passa, assim, a ser uma responsabilidade de todos os professores e de outros intervenientes que são chamados a participar do processo.

Situando-nos em concordância com esta visão, e acreditando, tal como Rodrigues (2018), que a inclusão não é um sonho, uma vez que a escola avançou nos processos inclusivos nomeadamente no respeito à individualidade de cada aluno, consideramos, contudo, que há ainda um longo caminho a ser trilhado.

É no quadro destas ideias que se reconhece pertinente a pesquisa que neste artigo se apresenta. Nele se discutem os Modelos Biomédico, Social e Biopsicossocial, enquanto possibilidade de leitura para a compreensão das respostas educativas construídas ao longo do tempo e para a compreensão da visão de professores sobre Inclusão e sobre possibilidades para a sua concretização.

\section{Modelos Biomédico, Social e Biopsicossocial e sua influência na educação escolar}

Políticas públicas e práticas de intervenção no campo da Inclusão Escolar surgem, muitas vezes, influenciadas por características ligadas aos Modelos Biomédico, Social e Biopsicossocial sendo, por esse motivo, fundamental apresentar esses conceitos, relacionando-os às formas de atendimento escolar que foram consolidadas ao longo do tempo. 
Na perspectiva de Engel (1977), o Modelo Biomédico possui forte influência da lógica mecanicista da revolução industrial, segundo a qual o corpo pode ser dividido em partes, cabendo às especialidades médicas responsáveis por cada parte "consertar" aquilo que não funciona corretamente. Nesse modelo, o indivíduo é visto como um ser passivo, cuja obrigação é procurar a cura ou condições mais próximas ao "padrão" reconhecido e valorizado pela sociedade como "normal" por meio da medicalização ou da reabilitação (BARROS, 2002; PUTTINI; PEREIRA; OLIVEIRA, 2010).

O Modelo Biomédico tem a Classificação Estatística Internacional de Doenças e Problemas Relacionados com a Saúde ${ }^{1}$ (CID) como referência. Um dos desdobramentos do Modelo Biomédico é o Modelo Caritativo. Nele a pessoa com deficiência é vista como vítima de alguma circunstância que a impossibilitou de viver a vida plenamente, assim ela precisa da caridade da sociedade (LARA, 2013).

Segundo Marco (2003), no cerne das normas legais e práticas de intervenção que visam à normalização dos indivíduos estão, muitas vezes, influências do Modelo Biomédico. $\mathrm{Na}$ área educacional, essas influências podem ser percebidas principalmente em normativos e práticas de intervenção balizados pela categorização dos estados de saúde para o provimento de respostas educativas, e pela supervalorização da reabilitação e de documentos que dependem do "ato médico", como o laudo.

Em alternativa ao Modelo Biomédico, surgiu o Modelo Social, motivado pela luta de diversos grupos sociais por igualdade, dentre eles o "Tetra Rolantes" da universidade de Berkeley nos EUA, em 1962. O movimento era composto por 7 alunos com diagnóstico de tetraplegia, e suas reivindicações consistiam basicamente na garantia de acessibilidade física aos ambientes universitários e na redução de atitudes discriminatórias. Foi, à data, criado o serviço de atendimento pessoal com o objetivo de os auxiliar a viver com autonomia. Esse movimento representou o início da luta pelos direitos civis das pessoas com deficiência nos EUA (MARCO, 2003). A partir de então, a participação das pessoas com deficiência nos mais variados espaços da sociedade, como a escola, passou a ser considerada como uma questão que requer mudanças atitudinais, ideológicas, sociais e políticas, alicerçadas no quadro dos direitos humanos e no respeito pela diversidade (LARA,

\footnotetext{
${ }^{1}$ A CID foi concebida pela Organização Mundial da Saúde (OMS) e está atualmente em sua 10a edição. Tem como propósitos descrever a etiologia das doenças, categorizando doenças e problemas de saúde. Fornece ainda dados estatísticos sobre mortalidade e morbidade, informação clínica sobre determinadas populações e dados epidemiológicos (OMS, 1997).
} 
2013). Na perspectiva do Modelo Social, estados de saúde e/ou situações que coloquem qualquer pessoa em desvantagem não podem impedir a concretização dos seus direitos, especificamente o direito à educação e à participação na escola (BAMPI; GUILHEM; ALVES, 2010; DINIZ, 2003).

Contudo, os pressupostos que alicerçam tanto o Modelo Biomédico quanto o Social não foram capazes de fornecer um quadro suficientemente claro para compreender a complexidade dos fenômenos ligados à inclusão/ exclusão. O reconhecimento dessa incapacidade levou a um novo debate sobre a necessidade de um enquadramento mais amplo, capaz de aglutinar os ganhos tanto do Modelo Biomédico, quanto do Modelo Social, impulsionando as discussões em torno de novas variáveis, que deram corpo ao Modelo Biopsicossocial (NUBILLA, 2010).

Em face dos argumentos aduzidos importa, então, explicitar diferenças entre os Modelos Biomédico, Social e Biopsicossocial. Enquanto o primeiro responsabiliza o indivíduo com algum tipo de AFEC pela sua reabilitação e medicalização, reforçando a categorização por tipos de deficiências, o segundo ressalta a responsabilidade da sociedade nos processos de exclusão, centrando o foco em intervenções nas estruturas e sistemas sociais (Saúde, Educação, Lazer etc) para a promoção de ambientes inclusivos. Por seu lado, o Modelo Biopsicossocial objetiva integrar o conhecimento dos campos Biomédico e Social sobre as formas de funcionamento, aprendizagem e interação, identificando, no caso da educação escolar, as acessibilidades necessárias para que cada aluno desenvolva o máximo de seu potencial, e promovendo ambientes pautados pelo respeito às diversidades (LARA, 2013).

O Modelo Biopsicossocial, segundo Puttini, Pereira e Oliveira (2010), comporta elementos do Modelo Biomédico, mas vai além dele quando considera a importância da compreensão de diversos condicionantes, como estados emocionais, socioeconômicos, educacionais, influências do meio social e das atitudes das pessoas que interagem socialmente para a construção de respostas educativas que potencializem 0 desenvolvimento das capacidades de cada aluno e fomentem a inclusão de todos os alunos. Segundo os mesmos autores, as características dos alunos interagem de modo dialético com o ambiente social, determinando, positiva ou negativamente, o impacto das situações vivenciadas na aprendizagem e participação. Por esse motivo, o Modelo Biopsicossocial está orientado para as intervenções no ambiente que possam reduzir 
barreiras e restrições à participação, à aprendizagem e interação, considerando também os fatores biológicos, pessoais, emocionais, familiares e socioeconômicos (OMS, 2003).

\section{Paradigmas da Exclusão (ou Segregação), Integração e Inclusão e sua relação com os Modelos Biomédico, Social e Biopsicossocial}

Ao longo dos tempos, a educação escolar pública, numa intencionalidade de "normalização", organizou-se segundo lógicas de atendimento que privilegiam os alunos que respondem positivamente a objetivos e métodos de um ensino padronizados, colocando à margem todos aqueles que, em decorrência de sua condição social, física e/ou intelectual são considerados incapazes de aprender pelos métodos tradicionais de ensino (THOMA, 2005). O significado de "normalização", segundo Silva (2019) consiste em:

\section{(...) aceitá-los [referindo-se às pessoas que não se enquadravam nos padrões valorizados pela sociedade] proporcionando-Ihes serviços da comunidade que contribuam para o desenvolvimento de suas possibilidades, de modo a que os seus comportamentos se aproximassem dos modelos considerados "normais". (SILVA, 2009, p. 139)}

Esta racionalidade normalizadora fundamentou vários paradigmas educacionais que, ao longo da história, têm legitimado o atendimento de crianças e jovens que não se encaixam nos padrões socialmente valorizados em cada época. Nesse percurso, de acordo com Sassaki (1999), podem ser identificados pelo menos três grandes paradigmas educacionais: o da Exclusão (ou Segregação); o da Integração e o da Inclusão. Ainda na perspectiva desse autor, o paradigma da Exclusão é fortemente influenciado pelo Modelo Biomédico, segundo o qual os alunos que não atendiam às expectativas socialmente reconhecidas pelo sistema escolar eram excluídos do acesso à escola, permanecendo segregados em seus lares ou em ambientes destinados à reabilitação.

Além da exclusão decorrente da presença de AFEC, dificuldades de aprendizagem, restrições no acesso e permanência dos alunos na escola, na sua participação ou interação com os pares, existem outras situações que podem impactar a exclusão educacional, ressaltando que a exclusão na escola tem grandes chances de se perpetuar na forma de exclusão social. Algumas dessas situações são a falta de acesso a espaços sociais e de lazer, a falta de acesso aos serviços de saúde, a violência, a exploração, a falta de vínculos afetivos, e a falta de cuidados básicos (ABRAMOVAY; MOLL, 2002).

A lógica da segregação passou a ser gradativamente substituída pela ideia de Integração quando possível (SASSAKI,1999). Na visão desse autor, a ideologia da 
Integração possível tinha a perspectiva de "normalização" subjacente em seu âmago, reforçando a ideia de que o indivíduo com AFEC deveria se "adequar" ao meio escolar, utilizando-se de recursos da reabilitação em saúde, buscando condições próximas ao que fosse tido como "normal" pela sociedade. Essa orientação pode ser associada à Multi Track Approach, enunciada no relatório da Agência Européia para o Desenvolvimento da Educação Especial (AEDEE, 2003). Esta abordagem define-se pela convivência entre dois sistemas, Escola Comum e Escola Especial, oferecendo grande diversidade de serviços e podendo vincular-se tanto ao Modelo Social, uma vez que preconiza a Integração de todos com todos, independente da presença ou não de AFEC, quanto ao Modelo Biomédico, uma vez que reforça a necessidade da reabilitação/instrumentalização no ambiente da Escola Especial.

Influenciado pelo Modelo Social, o paradigma da Integração emergiu nos Estados Unidos com a publicação da Public Law (1975), cujo propósito consistia em assegurar que todos os alunos com deficiência tivessem acesso a uma educação pública apropriada e gratuita, com ênfase na Educação Especial e em serviços pensados para o atendimento às necessidades de cada aluno, garantindo o exercício de seus direitos, enquanto cidadãos.

Na mesma direção, o Relatório Warnock (1978), publicado na Inglaterra, propôs uma abordagem de natureza educativa que previa a substituição da expressão "aluno com deficiência" por "alunos com Necessidades Educativas Especiais" (NEE), o que representou ruptura com o Modelo Biomédico, que atribuía ao indivíduo a responsabilidade por se adequar aos espaços e às formas de aprendizagem instituídas. Pese a compreensão de que a lógica trazida pela palavra "Especial", que até hoje vigora em muitos dos designativos que utilizamos como "Educação Especial", "Sala de Recursos Especiais", "Professor de Educação Especial", "Transporte Especial", "Escola Especial" etc, surge muito influenciada pelo Modelo Caritativo, fato que, na perspectiva de Lara (2013), pode ser entendido como um desdobramento do Modelo Biomédico.

Contudo, atribui-se ao Relatório Warnock (1978) um importante papel na educação, uma vez que responsabilizava os sistemas educativos pela criação de condições necessárias para a Integração de todos os alunos com NEE nas escolas comuns. A este propósito, nesse documento refere-se o seguinte:

Os sistemas de ensino são responsáveis pelo fornecimento de meios especiais de acesso ao currículo através de equipamento, instalações ou recursos, modificações do meio físico ou técnicas de ensino especial; acesso a um currículo especial ou adaptado; atenção especial à estrutura social e ao 
clima emocional nos quais se processava a educação (RELATÓRIO WARNOCK, 1978, p. 41).

Nesse âmbito são ainda produzidas outras recomendações, que passam pela necessidade de reavaliação de todos os alunos com deficiência que frequentavam escolas especiais, a fim de garantir a plena integração de todos em escolas comuns; são também sugeridas atividades de conscientização destinadas aos professores, no sentido de os capacitar para o uso de técnicas e estratégias pedagógicas diferenciadas.

No quadro dos pressupostos do paradigma da Integração, os atendimentos educacionais aconteciam em espaços específicos destinados a esse fim, sendo conditio sine qua non possuir um diagnóstico de foro médico, o que ressaltava as influências do Modelo Biomédico na determinação do acesso a qualquer tipo de suporte adicional no campo educacional que, via de regra, estava restrito à Educação Especial (JANNUZZI, 2004). Os atendimentos referidos aconteciam individualmente ou em pequenos grupos de alunos, organizados conforme o diagnóstico médico ou a natureza da dificuldade escolar, geralmente sob a responsabilidade de um professor especializado. A intervenção com esses alunos era organizada de modo a não incomodar os demais alunos da escola. Identificam-se nesta orientação aproximações à abordagem Two Track Approach (AEDEE, 2003), que se caracteriza pela existência de dois sistemas educativos independentes, indiciando influências do Modelo Biomédico, sob o qual as pessoas que não se enquadram nos padrões sociais estabelecidos devem restringir-se aos ambientes orientados para a reabilitação.

A presença de alunos com deficiência na escola comum não foi acompanhada por mudanças estruturais, ao nível do currículo e das estratégias pedagógicas, que proporcionassem a participação e interação de todos com todos e potencializassem a sua aprendizagem (JANUZZI, 2004; SILVA, 2009). Considera-se, neste âmbito, que as expectativas, metodologias, organização dos espaços e equipamentos, o currículo e a avaliação estavam pautados pela lógica da normalização dos indivíduos e pelo ideário da reprodução de valores que estimulavam a competição e a categorização (geralmente a partir dos deficits), perpetuando, muitas vezes, a exclusão daqueles que a escola deveria incluir (UNESCO, 2009).

Com efeito, embora se reconheçam inúmeros avanços no acesso e na ampliação da participação dos alunos com NEE na escola, permanecem ainda fragilidades nos sistemas escolares, que continuam a comprometer a efetividade da inclusão para cada aluno 
(CORREIA, 1997). Essa situação leva-nos a concordar com Patto (2000) que, amparandose em Bourdieu (1998), informa que a escola continuou a excluir de forma continuada, mantendo em seu âmago aqueles que dissimuladamente se propôs a incluir, condenando às margens aqueles que estão mais distanciados da "gramática escolar" e dos padrões socialmente aceitos.

A consciência desta realidade despertou para a importância de se produzirem respostas educativas adequadas às necessidades, ritmos e potencialidades de cada aluno, conduzindo à emergência do paradigma da Inclusão. Segundo ele, os sistemas educativos e as escolas devem proporcionar todos os meios, condições e recursos que garantam a inclusão de todos com todos, perspectiva alicerçada no respeito pela diversidade, almejando que os alunos alcancem o máximo de seu potencial (SASSAKI, 1999). Clarificando, Correia (1997) argumenta que

(...) a inclusão assenta nas necessidades da criança na sua totalidade no que respeita a três níveis de desenvolvimento essenciais: acadêmico, socioemocional e pessoal, orientada para a maximização do seu potencial. (CORREIA, 1997, p.34)

Na mesma linha, Booth e Ainscow (2002) acrescentam que a inclusão

(...) envolve mudanças e modificações no conteúdo, abordagens, estruturas e estratégias, com uma visão comum que abrange todas as crianças da faixa etária apropriada e uma convicção de que é responsabilidade do sistema regular educar todas as crianças. (BOOTH; AINSCOW, 2002, p.34)

Também Meyer, Rose e Gordon (2014) sustentam que abordagens diferenciadas, como o Desenho Universal para a Aprendizagem (DUA), pressupõem a construção de currículos e de estratégias metodologicamente flexíveis, viáveis a todos os alunos, diminuindo, assim, as barreiras que limitam o acesso, a aprendizagem e a participação de todos com todos.

Nas perspectivas teóricas apresentadas, reconhecem-se proximidades com a visão expressa no Policy Guidelines on Inclusion in Education. Nesse documento é enunciado que a inclusão é

(...) um processo que visa responder à diversidade de necessidades de todas as crianças e jovens, através de uma participação crescente na aprendizagem, culturas e comunidades, reduzindo e eliminando a exclusão dentro e fora da educação. (UNESCO, 2009, p. 8-9)

Em síntese, os fundamentos mobilizados permitem entender que a educação escolar de alunos que se encontram em situação de desvantagem em virtude da presença de AFEC ou de quaisquer outras situações que comprometam a sua aprendizagem, participação e 
interação passou a ser entendida numa perspectiva mais ampla, intitulada de inclusão. Essa perspectiva está em linha com os pressupostos da One Track Approach (AEDEE, 2003), que se caracteriza pela presença de todos os alunos no ensino comum, compartilhando os mesmos espaços, currículos e estratégias (respeitada a flexibilidade necessária de respeito às características individuais de cada aluno), o que demonstra a proximidade desse paradigma com os pressupostos do Modelo Biopsicossocial. Dito de outro modo, uma abordagem orientada pelos princípios de uma Educação Inclusiva e do Modelo Biopsicossocial preconiza a responsabilização dos sistemas, das organizações e dos profissionais de diferentes setores, como a Educação e a Saúde, que devem promover as condições necessárias ao desenvolvimento dos alunos por meio de respostas educativas pedagogicamente diferenciadas e da participação de diferentes intervenientes, como de profissionais da Saúde por meio do trabalho colaborativo.

\section{Procedimentos metodológicos}

O estudo que neste artigo se apresenta é de natureza qualitativa. Para a coleta de dados, recorreu-se à realização de entrevistas semiestruturadas com doze professoras que atuavam, há mais de cinco anos, na Educação Especial, em três Agrupamentos de escolas na região do grande Porto, Portugal.

Após o contato com os responsáveis pelos Agrupamentos de escolas e a obtenção da autorização para a realização das entrevistas, os objetivos da pesquisa foram esclarecidos e as participantes assinaram o Termo de Consentimento Livre e Esclarecido (TCLE). Tanto os responsáveis pelos Agrupamentos quanto os participantes foram ainda informados sobre os cuidados éticos, nomeadamente quanto ao anonimato e confidencialidade dos dados.

As entrevistas foram realizadas com recurso a um roteiro prévio, onde constavam perguntas orientadoras. Cada participante teve a liberdade de responder na sequência que melhor the conviesse.

Os discursos foram transcritos e analisados segundo a técnica da análise de conteúdo (BARDIN, 2009), com suporte do Software Nvivo. Para a mobilização dos discursos, e como forma de assegurar o anonimato, os entrevistados foram assim identificados: Entrevistado 1 (E1), Entrevistado 2 (E2), e assim sucessivamente. Os discursos foram organizados em duas categorias e uma subcategoria, que estruturam a apresentação e análise dos dados. 


\section{Apresentação e análise de dados}

A apresentação e análise dos dados foi feita em estreita articulação com os objetivos da pesquisa e estruturou-se em torno de duas categorias: 1) Inclusão: da ambiguidade discursiva às possibilidade de ação. Nessa categoria integra-se a subcategoria: Respeito à individualidade dos alunos; e 2) Modalidades de atendimento.

\section{Inclusão: da ambiguidade discursiva às possibilidades de ação}

De modo geral, os discursos das entrevistadas evidenciaram uma compreensão do conceito de escola inclusiva como um direito de todos os alunos, não restrito apenas a alunos atendidos no quadro da Educação Especial, tal como sugerem os seguintes excertos:

(...) parece-me haver uma preocupação mais redobrada com uma inclusão efetiva das crianças, não apenas os que têm necessidades educativas especiais, mas todos aqueles que, no fundo, estão em situação de risco de exclusão, ou que manifestem outro tipo de necessidades, a inclusão não se circunscreve à definição bio e psíquica, mas também à social, económica e cultural, entre outras. Portanto, às vezes, isto é um cluster de questões que acabam por abranger todos os alunos. (E2)

A escola está muito voltada, na minha perspectiva, para a inclusão, ou seja, ser uma escola para todos (...). (E8)

(...) hoje o grande pilar, a meu ver, é pôr a escola acessível a todos os alunos e a toda comunidade. E quando falo da comunidade refiro-me a todos, seja aqueles que têm dificuldades físicas, aqueles que têm problemas ao nível cognitivo, psicoemocionais também ou aqueles que estão acima da média, e que também precisam de ser incluídos. (E10)

Estes discursos mostram um entendimento de inclusão que, no campo da prática, parece enunciar a transição de um paradigma educativo restrito às AFEC, com forte influência do Modelo Biomédico, para outro, que preconiza processos educacionais sistêmicos e abrangentes, ancorados em pressupostos próximos ao Modelo Biopsicossocial. Podem também enquadrar-se na perspectiva de Booth e Ainscow (2002), ao reconhecerem o respeito da/pela diversidade e a inclusão como direito de todos.

Todavia, quando é solicitado às professoras que se pronunciem sobre os conceitos de Integração versus Inclusão, algumas revelaram certa ambiguidade conceitual, misturando argumentos que podem ser associados a um ou outro paradigma:

Também estamos a falar da integração. Por quê? Nós podemos pôr os alunos dentro de uma sala de aula, mas, a inclusão... é outra coisa, é estarem integrados nessa mesma sala. Mas, as pessoas podem estar a coabitar no mesmo espaço, estando incluídas, mas não estar integradas. Se eu trouxer um aluno com multideficiência para uma sala em que não haja materiais de 
apoio, materiais adaptados àquele aluno, àquela realidade, eu não vou integrar, posso ter incluído, mas não ter integrado. (E1)

A perspectiva é de inclusão, embora se perceba que em determinados casos não se verifique tanto a inclusão, mas mais um modelo integrativo. Mas apostamos sempre na integração o mais que pudermos. (E6)

Esta ambiguidade discursiva pode ser justificada pela própria concepção de Integração que, como sublinha Sassaki (1999), tem o seu alicerce na "aceitação dos diferentes" no espaço dos ditos "normais", sendo influenciada pelo Modelo Social, que marcou o acesso das pessoas com AFEC aos ambientes que antes eram exclusivos daqueles que se encaixavam nos padrões normativos e socialmente reconhecidos.

Outra inferência que pode ser feita a partir da análise destes excertos é a de que a concepção de inclusão para essas participantes se resume à ideia de colocar todos os alunos no mesmo ambiente, no caso, a sala de aula, medida que, por si só, não garante a inclusão, podendo, até, por vezes, representar profundas dificuldades a alunos que, por suas características, necessitam de ambientes e respostas mais estruturadas.

Quanto a essa alegação, importa ter presente que um dos objetivos centrais da inclusão é a promoção da aprendizagem, participação e interação de todos com todos. Contudo, no intuito de incluir, seria um grande equívoco desconsiderar situações complexas que poderiam expor os alunos a processos de exclusão, ou de não atendimento às suas condições individuais, incorrendo no erro de excluir do interior da escola aqueles que ela deveria incluir. Estes são argumentos que poderão fundamentar o posicionamento cético de algumas professoras relativamente à inclusão:

(...) não existe, na realidade, uma inclusão. E, depois, há uma perspectiva, que é: ajudem-na, porque há aqui uma pessoa que é diferente dentro desta sala e eu preciso de continuar o meu trabalho. E esta está aqui a mais. E, portanto, se houver Educação Especial, essa pessoa... a Educação Especial cuida. (E3)

(...) na integração, sim... porque a inclusão, efetivamente, não existe ainda. (E4)

(...) a inclusão é muito mais uma utopia do que concretamente uma realidade. (E7)

Hoje, aqui [em Portugal], acho que [a perspectiva] é a inclusão. Mas, efetivamente, a inclusão propriamente dita acho que ainda não se preconiza nas salas de aula. Acho que ainda há um longo caminho a percorrer. (E8)

Os dados permitem-nos inferir que, se por um lado, algumas professoras têm um entendimento amplo de inclusão, em linha com a visão de vários autores (SASSAKI, 1999; CORREIA, 1997; BOOTH; AINSCOW, 2002), por outro, há professoras que se revelam confusas e céticas. Esse ceticismo pode estar relacionado com certa incongruência que parece persistir entre os princípios da Educação Inclusiva enunciados, por exemplo, na 
legislação e diferentes modalidades de atendimento aos alunos com NEE na escola pública portuguesa.

Como evidenciaram os excertos mobilizados, embora as professoras se posicionem em acordo com concepções que valorizam a inclusão, elas parecem reconhecer que, na prática, permanecem abordagens enraizadas numa lógica de categorização dos alunos, assente mais nos seus deficits do que nas suas potencialidades, demonstrando claras influências dos Modelos Biomédico e Caritativo (LARA, 2013). Essa situação nos permite deduzir que alguns processos de intervenção continuam a desenvolver-se mais em proximidade com caraterísticas do Modelo Biomédico do que com o Modelo Biopsicossocial (MARCO, 2006; PUTTINI; PEREIRA; OLIVEIRA, 2010).

Reconhecemos, por isso, a importância de se continuar a apostar em processos de intervenção que a todos criem a oportunidade de interagir, de estar e de aprender juntos, concordando com Goffman (1998) quando sustenta que o conhecimento e a interação contribuem para reduzir o medo e o preconceito e, assim, potencializar a aprendizagem de todos, deslocando a importância da inclusão do campo individual e caritativo (em linha com o Modelo Biomédico) para o campo das conquistas de caráter coletivo, em linha com um Modelo Biopsicossocial. Ressaltando o caráter de transformação social que é inerente aos processos inclusivos.

\section{Respeito pela individualidade dos alunos}

A análise dos discursos demonstra, por um lado, que as professoras, na sua globalidade, reconhecem a importância de se atender às caraterísticas, ritmos e necessidades de cada aluno, numa perspectiva de Educação Inclusiva e, por outro, que a escola não está ainda preparada para esse desafio. Essa dupla leitura é demonstrada, de forma clara, pelas professoras entrevistadas:

(...) a inclusão de todos é fundamental, é importante respeitar as características de cada aluno, mas se pretendemos, de facto, uma inclusão, não é a pô-los a fazer um trabalho completamente marginal ao que a turma faz. A inclusão presspõe que eles estão envolvidos na turma, e que cabe ao professor, titular de turma, regular o tipo de tarefas, diferenciar o tipo de tarefas que este aluno deverá fazer, do ponto de vista do seu próprio currículo (...). (E3)

(...) fazer a inclusão é atender às características de cada menino (...) mas, as escolas não estão preparadas para ter todo o tipo de meninos, sobretudo quando vamos para os $2 . .^{\circ}$ e $3 . .-$ ciclos. Enquanto o Jardim de Infância e $011^{\circ}$ ciclo são escolas pequenas e em que a maior parte está adaptada para ter casos bastante graves, quando nós chegamos ao 2.ำ e ao 3.ำ ciclo e secundário, é completamente diferente. (E1) 
(...) Não posso, teoricamente, definir uma coisa quando eu não conheço as características dos alunos. É fundamental, eu acho. Acho que é preciso um tempo de conhecimento, para depois podermos planear. (E4)

(...) uma das coisas que eu acho fundamentais na inclusão é o respeito pela individualidade da pessoa. Por isso é que a palavra integração saiu de cena. Porque uma pessoa para estar incluída, de verdade, tem de haver respeito pela sua individualidade. (E5)

Como informam os excertos, o respeito pela individualidade dos alunos parece constituir um requisito para a sua inclusão que pressupõe reconhecer e respeitar a diversidade na sala de aula e recorrer a práticas de diversificação pedagógica, que potencializem que todos aprendam de modo significativo e se sintam incluídos. Essa posição é corroborada por Santos (2008), quando sustenta que, no atendimento de cada aluno, devem ser consideradas as suas características, necessidades e potencialidades, levando cada um a aprender e a desenvolver-se a partir das experiências que vivencia por meio de estratégias e técnicas pedagógicas diferenciadas.

\section{Modalidades de atendimento}

A ambiguidade que atravessa os discursos das professoras é simbólica da complexidade inerente aos processos de Inclusão. Essa complexidade repercute no modo como as instituições escolares e seus profissionais se organizam para responder às caraterísticas individuais dos alunos, seus interesses e ritmos de aprendizagem.

Atentando aos discursos das entrevistadas, percebem-se argumentos que parecem evidenciar diferentes modos de atender os alunos, como se nota a seguir:

Naquilo que diz respeito à escola, eu penso que a organização que regula, no fundo, a identificação de estratégias, de condições de integração, tem-nos feito perceber que nem sempre as escolas conseguem dar resposta àquilo que os alunos e crianças necessitam, nomeadamente ao nível das condições físicas das escolas. Desde obstáculos arquitetônicos, desde a própria configuração dos espaços. Todos aqueles obstáculos, escadas, janelas perigosas, etc., que não deveriam existir, mas, por várias razões, deparamonos com situações dessas que são difíceis de ultrapassar. (E2)

(...) porque um professor trabalha com um grupo, numa sala. $E$ tem de dar resposta a várias necessidades. Cada aluno tem uma necessidade específica, seja emocional, seja fisiológica, seja de outra ordem qualquer. E não consegue, de facto, fazer um atendimento sistemático que uma perturbação de linguagem necessita, por exemplo. Necessita de um treino sistemático para, por exemplo, uma perturbação articulatória grave tem de ser revertida, tem de ter um atendimento sistemático, que não é passível de ser feito num contexto de turma. (E3)

Neste momento, acho que há duas vertentes. Há a vertente da Educação Especial propriamente dita, em que os meninos estão dentro das salas incluídos, mas não existe, na realidade, uma inclusão. (E12)

Para mim, a ideia: ele [o aluno com deficiência] vai à sala, mas todas as crianças estão a desenvolver a atividade que toda a turma estiver a fazer não se justifica. E pode haver sempre um momento em que a turma faz uma 
atividade que se adequa àquela criança que tem multideficiência, porque também acaba por ser uma aprendizagem para quem não tem essas limitações todas. (E9)

(...) hoje [a escola] está muito voltada, na minha perspectiva, para a inclusão, ou seja, a escola ser acessível para todos, e não apenas a um grupo restrito que corresponde a um determinado padrão ou a um determinado perfil. (E11)

Se, por um lado, a ideia de "alunos de Educação Especial" e "os outros", parece estar presente nos depoimentos, e remeter para certa prevalência de modos de atendimento assentes no défict (Modelo Biomédico), por outro, vislumbram-se também preocupações de natureza mais inclusiva expressas na ideia de que "todos podem aprender juntos", numa orientação que se aproxima de fundamentos de uma Educação Inclusiva, aportada ao Modelo Biopsicossocial.

Relacionando ainda as visões das professoras com as abordagens expressas pela Agência Europeia para o Desenvolvimento da Educação Especial (AEDEE, 2003), elas podem estar situadas quer em proximidade com a One Track Approach, quer com a Two Track Approach, bem como com a Multi Track Approach.

Reconhece-se, assim, nos depoimentos apresentados, que a Educação Inclusiva configura-se como um campo extremamente complexo. Ao mesmo tempo em que se considera ser muito enriquecedor trabalhar para, e com, todos os alunos respeitando sua individualidade, propondo recursos de acessibilidade e respostas adequadas às dificuldades e potencialidade de cada um, admite-se também ser esse um enorme desafio, nomeadamente pela resistência à mudança inerente a muitas escolas e professores. Essa resistência pode ter diferentes origens, tais como: o caráter inconsequente das políticas públicas, diferentes concepções de Escola Inclusiva e sua influência nas práticas, estigmas e preconceitos sobre alunos, muito influenciados pela categorização e pela supervalorização das características de foro biomédico, etc. Estes e outros aspectos tendem a fazer com que muitos professores percam a esperança de que a Inclusão possa realmente ser efetiva para cada aluno, acabando por "delegar" a sua responsabilidade educativa para com os alunos com AFEC ao "professor de Educação Especial".

\section{Considerações finais}

A Educação Inclusiva e os processos para sua concretização, não sendo problemáticas novas, continuam a justificar investigações. Como ao longo da análise referimos, trata-se de um campo complexo, relativamente ao qual as escolas e os professores continuam a ser desafiados. Nessa trajetória, em harmonia com as diretrizes 
internacionais, Portugal, sobretudo depois da Lei de Bases do Sistema Educativo (PORTUGAL, 1986), foi construindo o seu caminho, instituindo legislação que pode ser associada quer a uma lógica integradora (PORTUGAL, 1991), quer a uma perspectiva inclusiva (Decreto-Lei n. 3/2008 e mais recentemente o Decreto-Lei n. 54/2018).

Com efeito, se do ponto de vista legislativo se reconhece haver um progressivo enquadramento rumo à filosofia da Educação Inclusiva, do ponto de vista das concepções das professoras, estas refletem uma certa ambiguidade, com reflexos na sua ação pedagógica.

Ainda assim, nos discursos percebem-se preocupações que parecem denotar uma transição do paradigma da Educação Especial, influenciado pelo Modelo Biomédico, para o paradigma da Inclusão, influenciado pelo Modelo Biopsicossocial, por meio da busca pela ampliação da capacidade de resposta por parte dos sistemas escolares, reduzindo a supervalorização das características ligadas aos diagnósticos e à reabilitação e estendendo a necessidade de respostas escolares ao nível da necessidade de cada aluno, independentemente da presença ou não de AFEC.

Esta observação parece ganhar relevância num momento em que em Portugal assiste-se à implementação do Decreto-Lei n.o 54/2018 que, em alinhamento com o compromisso com a Educação Inclusiva definido pela UNESCO (2009), aposta numa "escola inclusiva onde todos e cada um dos alunos, independentemente da sua situação pessoal e social, encontram respostas que Ihes possibilitam a aquisição de um nível de educação e formação facilitadoras da sua plena inclusão social" (Preâmbulo).

O protagonismo atribuído à escola na definição das respostas educativas é, sem dúvida, uma marca de ruptura com uma orientação que tornava o "professor de Educação Especial" o especialista responsável por "resolver" os deficits dos alunos (Modelo Biomédico), para que esses não "atrapalhassem" a aula dos demais, e que impulsiona uma visão de Educação Inclusiva (SASSAKI, 2006) num enquadramento sistêmico, de responsabilidade partilhada entre todos (escola, família, serviços da saúde, assistência social e comunidade), em linha com o Modelo Biopsicossocial (MARCO, 2006).

Reconhecendo que a vivência de uma plena inclusão pressupõe ainda percorrer um longo e sinuoso caminho, continuamos a acreditar na escola pública e nas possibilidades que oferece para, numa lógica de responsabilidade partilhada, encontrar respostas educativas promotoras de aprendizagens significativas para todos. Para nossa 
consideração final, apoiamo-nos em Abramowicz (1997, p. 89), quando sustenta que a "escola não pode tudo, mas pode mais, pode acolher as diferenças e tornar possível fazer uma pedagogia que não tenha medo do outro", em proveito de uma Educação Inclusiva.

\section{Referências}

ABRAMOVAY, Miriam; CASTRO, Mary Garcia; PINHEIRO, Leonardo de Castro; LIMA, Fabiano de Souza; MARTINELLI, Cláudia da Costa. Juventude, violência e vulnerabilidade social na América Latina: desafios para políticas públicas. Brasília: UNESCO/BID, 2002.

ABRAMOWICZ, Anete; MOLL, Jaqueline. (Org.). Para além do fracasso escolar. Campinas, SP: Papirus, 1997.

Agência Europeia para o Desenvolvimento em Necessidades Educativas Especiais (AEDNEE). Necessidades Educativas Especiais na Europa. (2003).Disponível em: https://www.european-agency.org/sites/default/files/special-needs-education-ineurope_sne_europe_pt.pdf.

AINSCOW, M. Tornar a escola inclusiva: como essa tarefa deve ser conceituada?. In: FÁVERO, Osmar et al. (Org.). Tornar a educação inclusiva. Brasília: UNESCO, 2009. p. 11-23.

BAMPI, Luciana Neves da Silva; GUILHEM, Dirce; ALVES, Elioenai Dornelles. Social model: a new approach of disability theme. Revista Latino-Americana de Enfermagem, v. 18, n. 4 , p. $816-823,2010$.

BARDIN, Laurence. Análise de Conteúdo. Lisboa: Edições 70, 2009.

BARROS, José Augusto C. Pensando o processo saúde doença: a que responde o modelo biomédico? Saúde e Sociedade, v. 11, n. 1, p. 67-84, 2002.

BOOTH, Tony; AINSCOW, Mel. Índex para a inclusão: desenvolvendo a aprendizagem e a participação na escola. Bristol: CSIE, 2002.

BOURDIEU, Pierre. (Org.). A miséria do mundo. Petrópolis/RJ: Vozes, 1998.

CORREIA, Luis Miranda. Alunos com NEE nas classes regulares. Porto: Porto Editora, 1997. 
DINIZ Débora. O modelo social da deficiência: a crítica feminista. Série Anis, n. 28, p. 1-8, 2003.

ENGEL, George Libman.The need for a new medical model A challenge for biomedicine. Science, v. 196, n. 4286, p. 129-136, 1977.

ESTADOS UNIDOS. Lei pública número 94.142 de 1975 [Public Law 94-142]. 0 ato de educação a todas as crianças portadoras de deficiência. Disponível em: https://www.govinfo.gov/content/pkg/STATUTE-89/pdf/STATUTE-89-Pg773.pdf.

FREITAS, Neli Klix. Inclusão socioeducativa na escola: avaliação do processo e dos alunos. Ensaio: Avaliação e Políticas Públicas em Educação, v. 16, n. 60, p. 323-336, 2008.

GOFFMAN, Erwing. Estigmas, notas sobre a manipulação da identidade deteriodada. 4. ed. Rio de Janeiro: Ed. Guanabara Koogan, S.A., 1998.

JANNUZZI, Gilberta de Martino. A educação do deficiente no Brasil: dos primórdios ao início do século XXI. Campinas, São Paulo: Autores Associados, 2004.

LARA, Luiz Fernando. gestão de pessoas e o desafio da inclusão das pessoas com deficiência: uma visão antropológica da deficiência. Revista Capital Científico Eletrônica, v. 11, n. 3, p. 121-142, 2013.

MARCO, Mario Alfredo de. A face humana da medicina: do modelo biomédico ao modelo biopsicossocial. São Paulo: Casa do Psicólogo, 2003.

MARCO, Mario Alfredo de. Do modelo biomédico ao modelo biopsicossocial: um projeto de educação permanente. Revista Brasileira de Educação Médica, v. 30, n. 1, p. 60-72, 2006.

MEYER, Anne; ROSE, David H.; GORDON, David. Universal design for learning: theory and practice. Wakefield: CAST Professional Publishing, 2014.

NUBILA, Heloísa Brunow Ventura Di. An introduction to the international classification of functioning, disability and health. Revista Brasileira de Saúde Ocupacional, v. 35, n. 121, p. $122-123,2010$.

OMS. Classificação Estatística Internacional de Doenças e Problemas Relacionados à Saúde. 10a rev. São Paulo: Universidade de São Paulo, 1997. 
NUBILA, Heloísa Brunow Ventura Di. Classificação Internacional de Funcionalidade, Incapacidade e Saúde-(CIF). São Paulo: Editora da Universidade de São Paulo, 2003.

OVIEDO, Rafael Antônio Malagón; CZERESNIA, Dina. O conceito de vulnerabilidade e seu caráter biossocial. Interface - Comunicação, Saúde, Educação, v. 19, n. 53, p. 237-49, 2015.

PATTO, Maria Helena Souza. Mutações do cativeiro: escritos de psicologia e política. São Paulo: Hacker, 2000.

PORTUGAL. Lei de Bases do Sistema Educativo, Lei n. ำ 46/86 de 14 de Outubro, 1986. PORTUGAL. Decreto-Lei nº 319/1991, de 23 de Agosto, Diário da República n. 123, 1aㅡ Série - A, Regime Educativo Especial, 1991.

PORTUGAL. Decreto-Lei nº3/2008, de 7 de Janeiro, Diário da República n. 4, 1ª Série Ensino Especial, 2008.

PORTUGAL. Decreto-Lei 54/2018. Estabelece os princípios e as normas relativos à

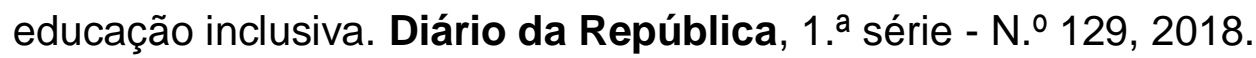

PUTTINI Rodolfo Franco; PEREIRA, Alfredo Junior; OLIVEIRA, Luiz Roberto de. Modelos explicativos em saúde coletiva: abordagem biopsicossocial e auto-organização. Revista Physis, v. 20, n. 3, p. 753-767, 2010.

RODRIGUES, David.Dimensões éticas da Educação Inclusiva. Revista Educação Inclusiva - Pró Inclusão, v. 8, n. 2, p. 11-17, 2017.

RODRIGUES, David.Inclusão: o elogio de uma certa forma de imperfeição. Revista Educação Inclusiva - Pró Inclusão, v. 9, n. 1, p. 7-8, 2018.

SANTOS, Leonor. Diferenciação pedagógica: um desafio a enfrentar. Noesis, n. 79, p. 5257 , 2009. em:

http://area.fc.ul.pt/pt/artigos\%20publicados\%20nacionais/Diferenciacao\%20Pedagogica\% 20Noesis.pdf

SASSAKI, Romeu Kazumi. Inclusão: construindo um a sociedade para todos. 3. ed. Rio de Janeiro: WVA, 1999. 
SASSAKI, Romeu Kazumi. Vida independente: história, movimento, liderança, conceito, filosofia e fundamentos. São Paulo: RNR, 2003.

SASSAKI, Romeu Kazumi. Inclusão: construindo uma sociedade para todos. 7. ed. Rio de Janeiro:WVA, 2006.

SASSAKI, Romeu Kazumi. Inclusão: acessibilidade no lazer, trabalho e educação. Revista Nacional de Reabilitação (Reação), ano XII, 2009, p. 10-16.

SILVA, Maria Odete Emygdio. Da exclusão à inclusão: concepções e práticas. Revista Lusófona de Educação, n. 13, p. 135-153, 2009.

SOUSA, Sthefany Aurora Dias Cand'; FARIA, Cleide Chagas da Cunha. Vulnerabilidades individuais e racionais entre adolescentes de uma escola pública. Revista Perquirere, v. 14, n. 1, p. 128-140, 2017.

THOMA, Adriana da Silva.Entre normais e anormais: invenções que tecem inclusões e exclusões das alteridades deficientes. In: PELLANDA, N. M.; SCHLÜNZEN, E.; JUNIOR, K. (Orgs.). Inclusão digital: tecendo redes afetivas/cognitivas. Rio de Janeiro: DP\&A, 2005. p. 253-274.

UNESCO. Declaração de Salamanca: sobre princípios, políticas e práticas na área das necessidades educativas especiais. Salamanca: UNESCO, 1994.

UNESCO. Organização das Nações Unidas para a educação, a ciência e cultura: policy guidelines on inclusive education. Paris: UNESCO, 2009.

UNESCO. A guide for ensuring inclusion and equity in education. Paris: UNESCO, 2013.

UNESCO. Marco da educação 2030: Declaração de Incheon. Incheon, Coréia do Sul: UNESCO, 2015.

WARNOCK, Helen Mary. Special education needs report of committee of enquiry into the education of handicapped children and young people. London: Her Majesty's Stationery Office. 1

\section{Correspondência}

Robson Celestino Prychodco - R. Tessália Vieira de Camargo, 126 - Cidade 
Universitária, Campinas - SP, 13083-887. CEPRE- Departamento de Desenvolvimento Humano e Reabilitação. Campinas, São Paulo, Brasil.

\section{(C) $(1) \otimes$}

This work is licensed under a Creative Commons Attribution-NonCommercial 4.0 International (CC BY-NC 4.0) 